\title{
IMMIGRANTS AND HEALTHCARE IN BULGARIA: THE RESPONSES BY POLICY AND LEGISLATION
}

\author{
Popova S., A. Kerekovska \\ Department of Social Medicine and Health Care Organisation, \\ Prof. Paraskev Stoyanov Medical University of Varna
}

\author{
Reviewed by: Assoc. Prof. T. Kostadinova
}

\begin{abstract}
The global scale of international migration flows has pushed migrants' health issues high up the policy agendas worldwide. Bulgaria as a new EU member-state is increasingly affected by immigration pressure. The health of migrants is acknowledged as an issue of major public health importance and a challenge for policy responses. The study aims to explore the existence of specific legislative regulations and policies developed in response to immigrants' health and healthcare services in Bulgaria, to identify the main problems and to highlight the challenges to both law and related policies. The methods involve comprehensive review and documentary analysis of international and national migrants' health literature; analysis of regulatory norms, specific policies and practices to assess the situation of immigrants' healthcare legislation and policy responses in the new context of Bulgaria's EU membership. The results reveal that legislative and multi-sectoral policy initiatives have been undertaken in Bulgaria to assure the protection of immigrants' health, nevertheless, there are problems emerging in practice, related to: deteriorated immigrants' health status; absence of consistent migration-management policy; lack of systematic reliable data, health information and rigorous research; insufficient interagency and international cooperation; lack of publicity and information about health insurance rights and obligations of immigrants and existing services; insufficient sensitivity and training of health professionals and relevant stakeholders. Promoting migrant-sensitive health policies; sensitizing and training health service providers and relevant policy-makers and stakeholders; encouraging research and information dissemination; increasing multi-sectoral involvement and expanding international cooperation on migrants' health are actions of recognized importance to better deal with immigrants' health problems in Bulgaria.
\end{abstract}

Key words: immigrants' health, legislation, policy, Bulgaria

\section{INTRODUCTION}

In recent years, the global scale of international migration flows has pushed migration issues high up the political agendas of governments worldwide. With the accession of 10 new member states to the EU in 2004 and two more in 2007 , migration has posed particular challenges to the enlarged European Union. The membership in the Union's political processes makes accession countries safer, the flow of capital and the development of the economic markets increase the demand for labour, and the social welfare system is becoming friendlier. It is expected, the changes will drive migration flows towards these countries, and this is the perspective to be kept in mind when designing migration policy and aligning to the Migration Acquis (1). Re-

Address for correspondence:

A. Kerekovska; Dept. of Social Medicine and Healthcare Organisation; Medical University Prof. Dr. Paraskev Stoyanov, 55 Marin Drinov St, BG-9002 Varna, BULGARIA;

e-mail: kerekovska_a@yahoo.com cently, the new member states of the EU are increasingly becoming target countries of migration. For their societies, this means a rapid change from countries almost without migration via strong emigration to more immigration in the future (11). This scenario requires preparation and careful planning and is a serious challenge for migration legislation and policy.

A major policy and legislation challenge of migration in Europe is immigrants' health. It is more than just a focus on disease entities; rather it includes wider determinants of health such as environmental, behavioural, socioeconomic and genetic-biological factors. It is also very much determined by the availability, accessibility and affordability of national health and social services, including services that facilitate integration to the host community (9). Migrants in Europe experience threats to their physical, mental, and social health and pose challenges to those seeking to protect their health as a human right (16).

Bulgaria, a new EU member state, is increasingly affected by immigration flows. The democratic changes and the 
processes of globalization have completely changed the migration situation in the country. Before 1989 Bulgaria, like the other former Soviet-bloc countries, was a country with limited migration. After 1989 the country became part of the European and the world migration system with intensive emigration flows (11). Now, after the accession to the European Union, the country is under increasing immigration pressure - becoming more attractive as both a transit and a final destination for immigrants.

The immigration phenomenon in Bulgaria is new and dynamic. Neither the institutionalisation nor the related studies measure up to its full scope and complexity. The registered number of immigrants in Bulgaria varies between 60 000 and 108000 for permanent foreign residents and between 30000 and 50000 for seasonal and irregular immigrants (12). The number of the foreigners seeking asylum in Bulgaria in the period 1993 - 2006 has been 15391, whereas refugee status has been granted to 1412 and humanitarian status to 3497 foreigners $(12,15)$. With regard to illegal migrants, it is estimated that their number varies between 30000 and 50000 persons $(2,14)$. An increase in the scope of immigration is expected in the following years with a view to the EU membership of the country.

The present paper sets out to review international and national documents, publications and relevant literature on immigrants' health legislation and policy, both in the EU and national contexts. It aims to explore the existence of specific legislative regulations and policies developed in response to immigrants' health and healthcare services in Bulgaria. The study also seeks to identify the main problems of immigrants' health in Bulgaria and to highlight the challenges to both law and related policies.

\section{MATERIAL AND METHODS}

The methods involve a comprehensive review and a documentary analysis of recent international and national migrants' health literature and documentation. An analysis of the regulatory norms and specific policies is applied to assess the situation of immigrants' healthcare legislation and draw up the picture of relevant policy responses in the new context of Bulgaria's EU membership.

\section{RESULTS AND DISCUSSION}

\section{The EU immigration policy framework}

During the last decade, the need for a common, comprehensive immigration policy has been increasingly recognised and encouraged by the European Commission and the EU Member States. The Commission has been therefore proposing concrete principles and measures - accompanied by a new strategy on immigration governance on which to base the further development of the common immigration policy over the coming years $(4,10)$. The European Union and its member-states have gradually established the foundations of a common legal framework on immigration and asylum. The complex and multifaceted nature of immigration has been acknowledged, requiring a mixture of policy actions covering a wide range of issues and fields: demographic constraints, economic needs, social expectations, health impacts, trade commitments, development needs, education opportunities, security dimension, etc. Prevention and access to healthcare by migrants has been seen as a prerequisite for public health of the EU, with significant positive impacts on its social, economic and political development, as well as on the promotion of human rights. Addressing the health of migrants has been also seen not only as a humanitarian cause, but moreover as a need for attainment of the best level of health and well-being for everybody living in the EU (4).

Therefore, numerous legislative and policy instruments have been developed at the European level recognizing the right to health as a fundamental human right for nationals and non-nationals alike with a goal to ensure protection of health and equitable access to health services of appropriate quality for all. Nevertheless, health inequalities between host populations and migrants, asylum seekers, refugees, victims of trafficking in persons and others in need of international protection and assistance continue to persist in the region, both in terms of health status as well as in access to health services of equal quality (10).

\section{Immigrants' health legislation framework in Bulgaria}

The new migration policy of Bulgaria is aimed at achieving an optimal balance between the freedom of movement of people and the control of illegal immigration while respecting the human rights and freedoms as guaranteed in international treaties and EU standards. The right to health and healthcare has been recognized as a fundamental right of immigrants. Specific legislative norms have been developed to regulate all strategies and actions adopted at national and regional level referring to migrants' health and healthcare services. The legislation regarding health insurance and medical services for foreigners who seek or have been granted protection in Bulgaria is regulated with details and is in line with the international and European practice in this area (2). The main legislative documents concerning immigrants' health are the: Constitution of the Republic of Bulgaria (3); 1951 Convention Relating to the Status of Refugees; Law on Asylum and Refugees (8); Foreigners in the Republic of Bulgaria Act; Law on Health (7); Law on Health Insurance (6); National Framework Contract (between the National Health Insurance Fund and the Union of Bulgarian Physicians); Ordinance on the access of health-insured persons to medical institutions for out-patient and in-patient medical assistance; Ordinance No40 of 24 Nov. 2004 laying down the basic package of healthcare activities guaranteed with the budget of the National Health Insurance Fund; Ordinance No2 of 27 April 2000 regarding the types of immunizations in Bulgaria and the terms for their delivery; Instructive Letter No91-01-242 of 15 October 2003 regarding the activity of NSSI's territorial units in relation to clarifying and proving the current health in- 
surance status of insured persons; Instructive Letter No91-01-19 of 19 Jan. 2004 of NSSI regarding the payment of health insurance contributions, etc.

The Constitution of the Republic of Bulgaria guarantees "the equal treatment of foreigners with respect to all rights and obligations" (3). The Act on Asylum and Refugees is the document that lays down the conditions and the procedures for granting special protection to aliens in the territory of the Republic of Bulgaria, as well as observation of their rights and obligations. Refugees have equal rights and obligations with the Bulgarian citizens, including rights to access and use of health care services, rights to social assistance, psychological assistance, health insurance, accessible medical care and free use of medical services under the procedure and within the extent applicable to Bulgarian nationals. In this document, the mandatory medical procedures for irregular migrants are also regulated (8).

\section{Immigrants' health insurance and healthcare services provision}

The well established legal framework in Bulgaria regulates the health insurance and healthcare services provision to migrants according to their official status: immigrants, asylum seekers, refugees (3).

\section{Immigrants}

The Law on Health contains a special provision regulating the equal rights in terms of medical services enjoyed by Bulgarian nationals and aliens who hold a long-term residence permit in Bulgaria (7). The Bulgarian legislation requires regular payment of health insurance contributions in order to avoid any discontinuation in the rights of health-insured persons. The health insurance rights and obligations of aliens are linked to their health insurance status. Main entry points to health care for immigrants are the general practitioners.

\section{Asylum-seekers}

The activities related to the medical services and health insurance for aliens who seek asylum are regulated in the Law on Asylum and Refugees (8) and the Law on Health Insurance (6). Main entry points to health care for asylum seekers and detained in prisons are the medical services and staff at the respective reception, integration or detention centre. The State Agency for Refugees (SAR), following the accommodation of asylum-seekers in the Registration-and-Reception Centres for Refugees, conducts compulsory medical checks and examinations in conformity with a Letter by the Ministry of Health (including tests for AIDS, syphilis, parasitoses, malaria). There are medical facilities at the Registration-and-reception centres, with isolation wards for persons with contagious diseases and asylum-seekers who need everyday medical care and observation. Where necessary, medicines for the treatment of urgent cases are secured. Foreigners accommodated in these centres receive mandatory medical examination by a doctor working for the respective Regional Directorate of Interior. As from the date of opening the status determination proce- dure, the SAR makes the monthly compulsory health insurance contributions for asylum-seekers by using resources from the state budget. After receiving the temporary refugee certificate, asylum-seekers are referred to choosing a GP. Pursuant to the Law on Asylum and Refugees and the Law on Health Insurance, pending the status determination procedure, the asylum-seekers have the same rights and access to medical assistance and free-of-charge medical services under the procedure applicable to Bulgarian nationals.

\section{Aliens who have been granted protection in the Republic of Bulgaria}

Aliens who have been granted refugee or humanitarian status have the same rights and obligations as Bulgarian nationals in the area of health insurance and access to medical assistance. The State Agency for Refugees terminates the payment of monthly health insurance contributions as from the date of submission of the decision granting the status. The aliens who have been granted protection are obliged to pay health insurance contributions under the procedure regulated in the Law on Health Insurance. The health-insured aliens who have been granted refugee or humanitarian status are entitled to medical assistance within the basic package of health activities guaranteed with the budget of the National Health Insurance Fund. In cases, when additional payment for medical services has to be made outside the basic package guaranteed with the budget of the National Health Insurance Fund, the State Agency for Refugees seeks the support of various sponsors. For instance, the Refugee-and-Migration Service of the Bulgarian Red Cross ensures out-patient and in-patient treatment, training on family planning and prevention of STDs, psychiatric aid, etc. on the basis of contracts with medical centres (13).

\section{Programmes and policies related to immigrants' health}

A great number of initiatives have been undertaken in Bulgaria to assess the major health problems of migrants and refugees as well as to assure high level of protection of their health. These actions are based on the recommended good practices of the EU Member States for delivering health services to foreigners looking for protection as well as to refugees and alylum seekers referring to a broad range of political areas like employment, health, work safety and protection, education, social protection and delivery of health care. Such are: development and enforcement of legal framework regulating migrants' rights and access to health care; ensuring equal and complete access to health care; provision of medical check-up exams and investigation to the new immigrants; raising health service providers' and professionals' cultural sensitivity to migrants' health issues; training health professionals on refugees' specific health issues and needs; training and inclusion of experienced refugees as mediators in the process migrants' healthcare provision; development and dissemination of information materials regarding refugees' rights in the area of health insurance and healthcare; enhancing capacity of 
non-governmental organizations to support the social integration of migrants and facilitate their equitable access to health promotion and care (2).

A National Program for the Integration of Refugees in Bulgaria 2005-07 has been formulated on the basis of an in-depth analysis of the legal framework and the practice, which contains the main principles and aims with regard to refugees' integration in Bulgaria. It also includes activities related to migrants' health and healthcare services (5). Other programmes and projects relevant to the health of immigrants in Bulgaria are the Program "Prevention and Control of HIV/AIDS", financed by the Global Fund to Fight AIDS, Tuberculosis and Malaria, 2007; the Research project of the Bulgarian Helsinki Committee on the rights of immigrants in Bulgaria (including rights to health and healthcare services) 2005 - supported by Open Society, Budapest, and the UNHCR and the Red Cross project in Bulgaria "Local Integration of Refugees in Bulgaria" - facilitating medical assistance and provision for reimbursement of medicines (2)

A relatively high number of NGOs are also involved in policies related to immigrants' health in Bulgaria.and are operating in the refugee field. The Bulgarian Red Cross (a UNHCR non-governmental partner in the country) and its Refugee Migrant Service aims to facilitate the integration of refugees in Bulgaria, prevent the isolation of migrants and promote tolerance towards both groups in Bulgarian society. It also assists refugees with physical and mental health services, in-kind goods (food, clothes), Bulgarian language courses, professional and vocational training, social counselling, etc. Another visible NGO is the Bulgarian Helsinki Committee for Human Rights which has also established a refugee migrant service acting in this field.

\section{Problems and challenges}

Despite all relative initiatives, there are some problems emerging in practice - related to the medical services for immigrants and their specific needs. Such are:

- Absence of consistent migration-management policy A well-formulated and consistently implemented migration management policy is lacking in Bulgaria. The changes of the Bulgarian legal framework so far have been prompted solely by the EU accession process and although legislative harmonization has undoubtedly been a positive development, it cannot be hailed as a substitute for a national migration management policy tailored to the specific economic and social context in which such legislation is to be implemented. This apparent policy gap has lead to the unproductive casting of migration into a predominantly law-enforcement framework, which seeks to prevent and restrict migration flows into the country, rather than to manage and facilitate them to its advantage (2).

- Deteriorated immigrants' health status - Many foreigners who seek or have been granted protection have a deteriorated health status as a result of malnutrition, unsatisfactory medical care in their countries of origin, the difficult transition conditions in
Bulgaria, chronic diseases, stress, etc. Asylum-seekers come from countries with region-specific diseases, which require diagnosis and treatment (16).

- Lack of migrant-sensitive health services and insufficient sensitivity and training of health professionals and relevant stakeholders - There is a need to reach out to migrants and address their special vulnerabilities and health-care needs. A major problem in this process is the insufficient sensitivity and training of health professionals and the linguistic barrier between the medical staff and the aliens who seek or have been granted protection. Apart from sensitizing and training health service providers and relevant policy-makers and stakeholders, the response also entails targeting interventions to reduce migrants' health risks and launching "migrant-sensitive" programmes and services, which include care that takes cultural, religious and linguistic needs into consideration.

- Lack of publicity and information about health insurance rights and obligations of immigrants and existing services. The immigrants are not familiar with their health insurance rights and obligations, which does not allow them to make use of the basic package of health activities guaranteed with the budget of the NHIF (2). A great part of the medical specialists are also not well familiar with the healthcare rights of refugees and asylum seekers in Bulgaria.

- Lack of systematic reliable data, health information and rigorous research. Systematic and rigorous research on short- and long-term resident foreigners is lacking in Bulgaria. Health information on migrants' health and on their access to health services is scarce. Due to a lack of precise unified methodology for analysing migration movements and co-ordination between institutions observing these movements the official data is not completely reliable. The data available in the public domain through various unofficial channels is scarce and controversial (2). Accurate research and reliable statistics are vital to the formulation of a coherent migration policy. Moreover, such data is essential in order to ensure that government bodies dealing with immigration receive adequate budgetary allocation to implement the policies and measures envisaged by it.

- Insufficient interagency and international cooperation and lack of adequate institutional structure for meeting immigrants' needs. A paradoxical level of institutionalisation is obvious for the Bulgarian situation, characterized by a small number of refugees but a developed set of governmental and non-governmental, national and international, organisations; and on the other hand - a growing number of immigrants but just the first slow steps in creating an adequate institutional structure for meeting their needs (10). There is a clear necessity for strengthening interagency, interregional and international cooperation on migrants' health emphasizing on developing partnerships with other organizations such as UNHCR and the International 
Immigrants and Healthcare in Bulgaria: The responses by policy and legislation

Organization for Migration and promoting cooperation for health policies among central and local governments as well as among representatives of civil society.

- Insufficient multi-sectoral action and policies for solving migrants' health problems. Interventions that address the social determinants of health are needed through intersectoral actions that target the causes at societal level. The economic, political, social and environmental determinants of migrants' health underline the importance of developing intersectoral policies.

\section{CONCLUSION}

There are visible signs of the growing attractiveness of Bulgaria as a final destination country for immigrants with its accession to the EU. The number of non-nationals coming to Bulgaria for permanent and long-term residence has been gradually increasing. European policies and legislation in the field of migration have been developing very dynamically with the expansion of the Union, and Bulgaria is making a serious effort to follow these developments.

The issues related to immigrants' health are increasingly acknowledged as a national public health problem of substantial significance. In this aspect, a great number of initiatives have been undertaken in Bulgaria to assure the protection of immigrants' health, nevertheless, there are problems emerging in practice that represent a challenge for future policy responses.

A well-formulated and consistently implemented migration management policy is need that encompasses a coordinated, comprehensive, multi-sectoral policy approach for improving migrants' health. As migration has linkages with various policy areas - social, economic, political, trade, labour, public health and security ones - a successful migration management policy should adopt a holistic approach, which takes into account all cross-cutting issues and areas.

Advocating migrants' health rights and equitable access to health protection and care; promoting migrant-sensitive health policies; initiating or reinforcing migrant-friendly public health services and health care delivery methods for migrants with special needs; sensitizing and training health professionals in addressing the health aspects associated with population movements; strengthening health promotion and disease prevention initiatives to reach out to migrants in the community; establishing minimum standards of health care for all vulnerable migrant groups; encouraging research and information dissemination and health and migration knowledge production; establishing and maintaining adequate institutional structure for meeting immigrants' needs; increasing multi-sectoral involvement and expanding interagency and international cooperation on migrants' health are among the actions of recognized im- portance to better deal with immigrants' health problems in Bulgaria.

\section{REFERENCES}

1. Brady H. EU Migration Policy: An A-Z. Centre for European reform. Briefing. London, 2008. (http://www.cer.org.uk/pdf/briefing_813.pdf).

2. Bulgarian Helsinki Committee. Research of the rights of migrants in Bulgaria from a human rights perspective. Migrants' rights report, Sofia, Nov. 2006.

3. National Assembly of the Republic of Bulgaria. The Constitution of the Republic of Bulgaria. Prom. SG 56/13 Jul 1991, last amend. SG 12/6 Feb 2007. (http://www.parliament.bg/?page=const \&lng=en).

4. Council of Europe. A Common Immigration Policy for Europe. MEMO/08/402 Brussels, 17 June 2008 (europa.eu/rapid/pressReleasesAction.do?reference $=\mathrm{MEMO} / 08 / 402$ ).

5. Council of Ministers. National Program for the Integration of Refugees in Bulgaria 2005-07.Sofia, Bulgaria. (http://www.unhcr.bg/pib/index.htm).

6. Government of Bulgaria. National Health Insurance Act. State Gazette No 70, 19 June 1998, Sofia, 1998.

7. Government of Bulgaria. Law on Health. State Gazette No 70, 10 August, 2004, Sofia, 2004.

8. Government of Bulgaria. Law on Asylum and Refugees. State Gazette No 54, 31 May 2002, last amend. 29 June 2007.

9. IOM 2006. World Migration Report - Costs and benefits of international migration. (http://images.gmanews.tv $/ \mathrm{html} / \mathrm{research} / 2007 / 12 /$ world_migra tion_report_2006.htm).

10. IOM. Migration Initiatives: Appeal 2008. (www.iom.int/published_docs/studies_and_reports/MI2008_UPDATED.pdf).

11. Krusteva, A. 'The Bulgarian Immigration Phenomenon'. In Immigration in Bulgaria, ed. A. Krusteva, 19-73. Sofia: IMIR, 2005.

12. National Statistical Institute. Population and demographic processes. Sofia, NSI, 2006.

(http://www.nsi.bg/Population/Population.htm).

13. Sabeva, K., Radeva, M. Practical aspects of health insurance and healthcare for aliens who have been granted refugee status or humanitarian status in the Republic of Bulgaria - Report. Sofia, 2005.

14. State Agency for Refugees (Official website). Statistics and Reports. (http://aref.government.bg/ ?cat $=21$ ).

15. UNHCA (The UN Refugee Agency). Asylum Trends in Central and Eastern Europe in 2005 - 2007. (http://www.nrc.org.co/biblioteca/Informe-ACNUR-2 008.pdf).

16. WHO. 61st World Health Assembly. Health of migrants. Report by the Secretariat. A61/12; 7 April 2008.

(http://www.who.int/mediacentre/events/2008/wha61/ journal3/en/index.html). 